\title{
The Soto Ramp for Neonatal Lumbar Punctures
}

\author{
Larry Mellick* and Mario Soto \\ Department of Emergency Medicine, University of South Alabama, USA
}

Submission: July 26, 2018; Published: September21, 2018

*Corresponding author: Larry Mellick, Professor of Emergency Medicine and Pediatrics, University of South Alabama, Department of Emergency Medicine, USA, Medical Center 2451 Fillingim Street, Mobile, AL 36617, Tel:251/470-1649 or706-533-2931; Email: Imellick@health.southalabama.edu

\section{Introduction}

Lumbar punctures are commonly performed in the pediatric emergency department in neonates and infants.Multiple studies have looked at patient positioning to maximize interspinous distance, and the consensus is that hip flexion in the seated upright position provides the largest space in which to introduce a Lumbar Puncture (LP) needle.We will review the current literature and propose an idea on patient positioning to increase hip flexion and make the collection of Cerebrospinal Fluid (CSF) easier.

\section{Discussion}

The positioning of neonates for the lumbar puncture procedure seems to be very much an issue of personal preference. In fact, most clinicians use the flexed lateral decubitus position for neonatal LP's[1] but the evidence from a number of prospective and observational studies suggests for several reasons that the upright sitting position with knees maximally flexed is the best.
In a 2010 publication, Abo et al. [2] utilized portable ultrasound to evaluate pediatric subjects in 5 different positions. Their results demonstrated that hip flexion, both in the seated and lateral recumbent position, significantly increased interspinous space. However, maximum interspinous space was achieved when the subject was seated with flexed hips.Other studies confirm these findings for both neonates and adults [2-6]. Whether or not the increased interspinous space translates to greater success is not clear.In fact, both a retrospective and prospective randomized trial by Hanson et al. [7] suggests that that the seated, upright position may not improve the success rate of neonatal lumbar punctures as compared to the lateral decubitus position.Nevertheless, both of these studies acknowledged an important limitation.The authors acknowledged that the operators were possibly less experienced with the upright position as compared to the more popular lateral decubitus position. Consequently, the providers' familiarity with the lateral position might have biased their results toward more success in that position(Figure 1)[7,8].

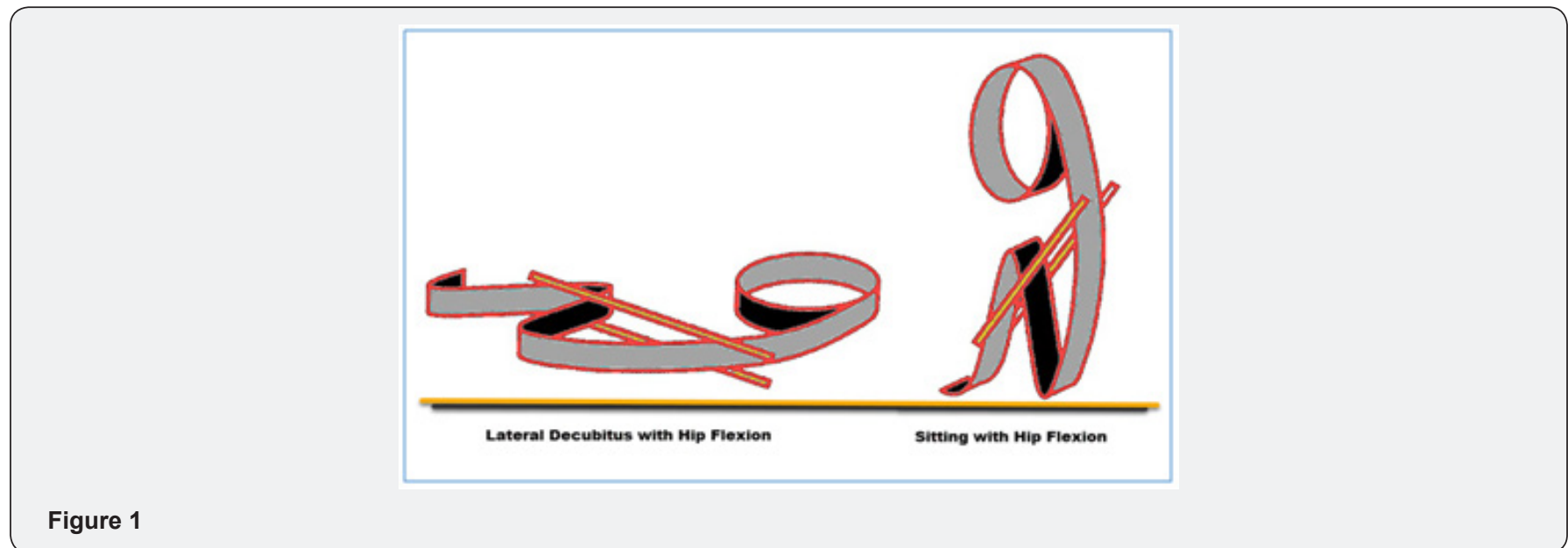

Nevertheless, there are other excellent and evidence-based reasons for recommending the upright position for neonatal lumbar punctures.First, the risk of oxygen desaturations is less with the seated upright position as compared to the lateral decubitus position. Gleason et al. [1] found that oxygen desaturations were significantly less common in the upright position when the sitting upright position was compared against two lateral recumbentpositions in preterm infants undergoing lumbar puncture[1]. In another randomized controlled trial by Weisman et al. [9]26 neonates with illness receiving LP were studied in the sitting, lateral knee-chest or lateral without kneechest positions. The mean transcutaneous oxygen pressure was lowest in the lateral knee-chest position as compared to the other two positions(Figure 2)[9]. 


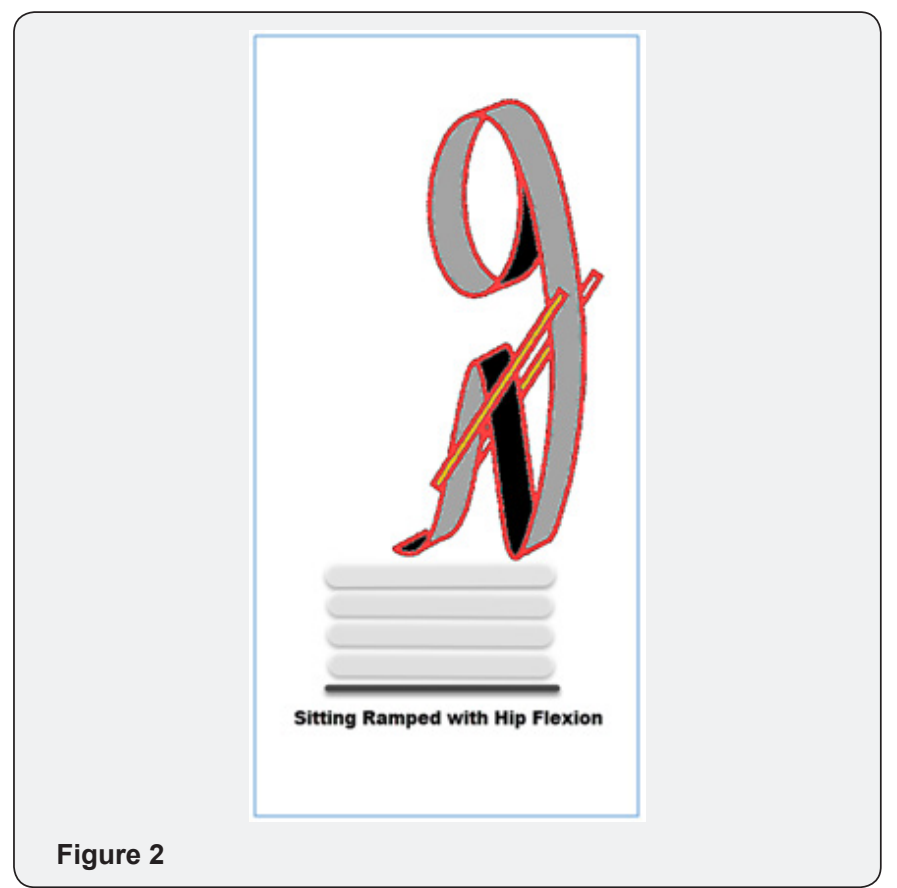

Additionally, it is the author's opinion that the upright seated position allows the easiest identification of iliac crest and vertebral spinous process landmarks as well as monitoring of the shoulders for unwanted rotation or loss of vertical straightness to the vertebral column.

\section{TheSotoRamp}

The positioning of an infant or neonate in the seated position with flexed hips while maintaining adequate room for CSF collection is difficult to achieve without an adjunct.It is possible that this position can occur by ramping with folded sheets under the infant and allowing the infant's buttock to slightly hang over the edge.In this paper we introduce the Soto ramp concept for neonatal lumbar punctures.There are at least three potential benefits of this technique.

i) The upright infant's knees can be maximally flexed if the buttocks are allowed to slightly hang over the edge of the stacked towels.

ii) Without the Soto ramp the lumbar puncture needle extending from the lower back can often be located only centimeters from the bed. The ramp elevates the spinal needle draining Cerebral Spinal Fluid (CSF) from the back several inches from the flat surface of the bed and allows greater space for maneuvering the tubes used to collect the dripping CSF.

iii) The holder of the infant is allowed a comfortable padded ramp on which to stabilize his or her hand forearms and hands that are grasping the infant's arms and legs. Since lumbar puncture success is anecdotally often attributed to the skills of the healthcare provider holding the infant, this may be an especially important contribution(Figure 3).

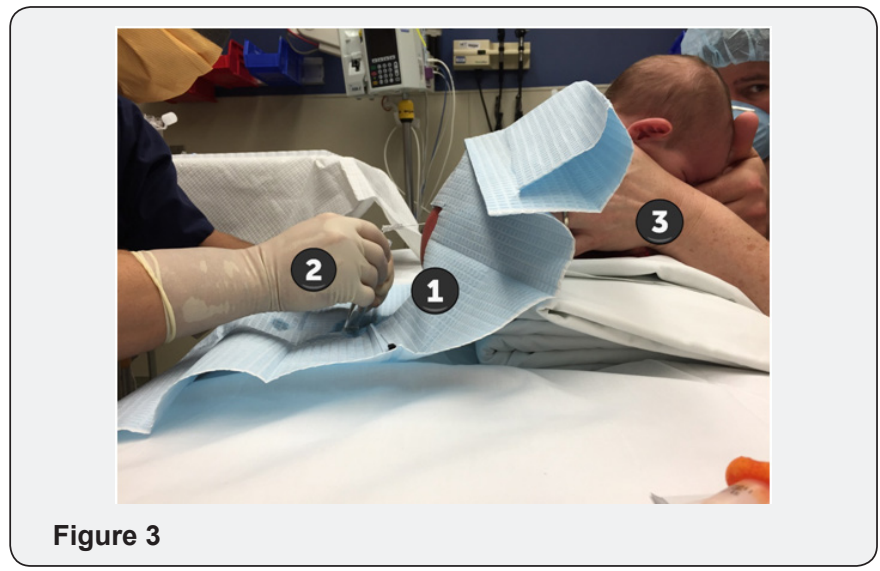

Summary

In summary, the seated upright, hips flexed position allows the greatest possible interspinous width for adults, children and infants. And, the wider the interspinous space theoretically gives the best possible conditions for entering the spinal canal and a successful spinal tap. The Soto Ramp for neonatal lumbar puncture is a refinement to upright knees flexed position.Maximal knee flexion, a greater distance between the gurney mattress and the needle allowing safer maneuvering of the CSF tube and a more comfortable arm support for the operator holding the infant are accomplished with this technique.

For a video describing the technique: https://www.youtube. com/watch?v=TVPtC2SIY8o

\section{References}

1. Gleason CA, Martin RJ, Anderson JV, Carlo WA, Sanniti KJ, et al. (1983) Optimal position for a spinal tap in preterm infants. Pediatrics 71(1): 31-35.

2. Abo A, Chen L, Johnston P (2010) Positioning for Lumbar Puncture in Children Evaluated by Bedside Ultrasound Pediatrics 125: e1149.

3. Oulego Erroz I, Mora Matilla M, Alonso Quintela P, Rodríguez Blanco S, Mata Zubillaga D, et al. (2014) Ultrasound evaluation of lumbar spine anatomy in newborn infants: implications for optimal performance of lumbar puncture. J Pediatr 165(4): 862-865.

4. Öncel S, Günlemez A, Anik Y, Alvur M (2013) Positioning of infants in the neonatal intensive care unit for lumbar puncture as determined by bedside ultrasonography. Arch Dis Child Fetal Neonatal Ed 98(2): F133-F135.

5. Sandoval M, Shestak W, Sturmann K, Hsu C (2004) Optimal patient position for lumbar puncture, measured by ultrasonography. Emerg Radiol 10(4): 179-181.

6. Fisher A, Lupu L, Gurevitz B, Brill S, Margolin E, et al. (2001) Hip flexion and lumbar puncture: a radiological study. Anesthesia 56(3): 262-266.

7. Hanson AL, Ros S, Soprano J (2014) Analysis of infant lumbar puncture success rates: sitting flexed versus lateral flexed positions. Pediatr Emerg Care 30(5): 311-314.

8. Hanson AL, Schunk JE, Corneli HM, Soprano JV (2016) A Randomized Controlled Trial of Positioning for Lumbar Puncture in Young Infants. Pediatr Emerg Care 32(8): 504-507.

9. Weisman LE, Merenstein GB, Steenbarger JR (1983) The effect of lumbar puncture position in sick neonates. Am J Dis Child 137(11): 1077-1079. 

CC (1) This work is licensed under Creative BY DOI: 10.19080/JAICM.2018.07.555718
Your next submission with Juniper Publishers will reach you the below assets

- Quality Editorial service

- Swift Peer Review

- Reprints availability

- E-prints Service

- Manuscript Podcast for convenient understanding

- Global attainment for your research

- Manuscript accessibility in different formats

( Pdf, E-pub, Full Text, Audio)

- Unceasing customer service

Track the below URL for one-step submission https://juniperpublishers.com/online-submission.php 